\title{
Farnesylated RhoB inhibits radiation-induced mitotic cell death and controls radiation-induced centrosome overduplication
}

\author{
J Milia ${ }^{1}$, F Teyssier ${ }^{1}$, F Dalenc ${ }^{1}$, I Ader ${ }^{1}$, C Delmas ${ }^{1}$, A Pradines ${ }^{1}$, \\ I Lajoie-Mazenc ${ }^{1}$, R Baron ${ }^{1}$, J Bonnet ${ }^{2}$, E Cohen-Jonathan', \\ G Favre ${ }^{1}$ and $C$ Toulas ${ }^{*, 1}$ \\ 1 INSERM U563, CPTP, Département d'Innovation Thérapeutique et \\ d'Oncologie Moléculaire, Institut Claudius Regaud, 20-24 rue du Pont St \\ Pierre, 31052 Toulouse Cedex France \\ 2 Département de Radiothérapie, Institut Claudius Regaud, 20-24 rue du Pont St \\ Pierre, 31052 Toulouse Cedex France \\ * Corresponding author: C Toulas, INSERM U563, Département d'Innovation \\ Thérapeutique et d'Oncologie Moléculaire, Institut Claudius Regaud, 20-24 rue \\ du Pont St Pierre 31052 Toulouse, France. Tel: + 335614242 75; \\ Fax: + 335614246 31; E-mail: toulas@icr.fnclcc.fr
}

Received 09.7.04; revised 03.1.05; accepted 14.1.05; published online 18.3.05 Edited by W El-Deiry

\section{Abstract RhoB is present in both a farnesylated and a geranylger- overduplication following irradiation mediated by the Rho- cellular resistance to radiation-induced nonapoptotic cell death. \\ Cell Death and Differentiation (2005) 12, 492-501. \\ doi:10.1038/sj.cdd.4401586 \\ Published online 18 March 2005}

Our previous results demonstrated that expressing the GTPase ras homolog gene family, member B (RhoB) in radiosensitive NIH3T3 cells increases their survival following 2 Gy irradiation (SF2). We have first demonstrated here that RhoB expression inhibits radiation-induced mitotic cell death. anylated form in vivo. By expressing RhoB mutants encoding for farnesylated (RhoB-F cells), geranylgeranylated or the CAAX deleted form of RhoB, we have then shown that only RhoB-F expression was able to increase the SF2 value by reducing the sensitivity of these cells to radiation-induced mitotic cell death. Moreover, RhoB-F cells showed an increased G2 arrest and an inhibition of centrosome kinase, strongly suggesting that RhoB-F may control centrosome overduplication during the G2 arrest after irradiation. Overall, our results for the first time clearly implicate farnesylated RhoB as a crucial protein in mediating

Keywords: mitotic cell death; ionizing radiation; Rho B; centrosome duplication; radioresistance

Abbreviations: $\mathrm{CAAX}, \mathrm{C}=$ cysteine $\mathrm{A}=$ aliphatic amino acid, $X=$ any amino acid; DMEM, Dulbecco's modified Eagle's medium; FTI, farnesyltransferase inhibitors; PBS, phosphatebuffered saline; PI, propidium iodide; RhoB, ras homolog gene family, member B; ROCK, Rho kinases; SF2, surviving fraction after a 2 Gy irradiation

\section{Introduction}

When exposed to ionizing radiations, mammalian cells activate DNA repair mechanisms to protect their genome integrity. These repair mechanisms can function during the G1/S or G2/M cell cycle arrests induced by ionizing radiation, although some lesions are irreparable and lead to cell death either by apoptosis or by mitotic cell death. While apoptosis is the universal pathway followed by hematopoietic cells after irradiation, mitotic cell death is the characteristic form of death of cells within solid tumors induced by irradiation ${ }^{1,2}$ and the major response to exposure to different anticancer drugs. ${ }^{3-7}$ It is now accepted that this type of cell death results from aberrant mitoses following irradiation. Such mitoses that fail to produce correct chromosomal segregation lead to the formation of large nonviable cells with several nuclei. ${ }^{8}$ The appearance of these giant multinucleated cells, and, in consequence, mitotic cell death, has recently been associated with an abnormality of centrosomal duplication during the cell cycle following irradiation. ${ }^{9,10}$ However, despite these recent data, the molecular mechanisms controlling this type of cell death are still largely unknown.

Our previous works have demonstrated that radiationinduced mitotic cell death is modulated by treating radioresistant cells with farnesyltransferase (FTase) inhibitors (FTIs). FTase catalyzes the covalent binding of a 15-carbon prenyl at the cysteine in the $\mathrm{COOH}$-terminus in a CAAX sequence ( $\mathrm{A}$ is an aliphatic acid, $\mathrm{X}$ is methionine or serine). This post-translational modification is required for the biological activity of certain proteins such as Ras. FTIs, which are selective for FTase over the closely related family member, protein geranylgeranyltransferase, have been developed initially as potential anticancer drugs. However, it has since been shown that this class of compounds elicits a radiosensitizing effect not only in mutated-Ras-expressing radioresistant tumor cell lines ${ }^{11,12}$ but also in wild-type Ras-expressing radioresistant tumors of the uterine cervix or of glioblastoma cells. ${ }^{6,7}$ We have previously demonstrated that this radiosensitizing effect of FTIs on wild-type Rasexpressing cells was due to the induction of radiation-induced mitotic cell death, strongly suggesting that a farnesylated protein might be involved in controlling these mechanisms. ${ }^{6,7}$ In terms of identifying this farnesylated protein, the small GTPase ras homolog gene family, member $B(R h o B)$ appears to be potentially a very interesting candidate. RhoB is a member of the Rho family of GTPases that regulate cytoskeletal actin, focal adhesion formation, proliferation, cell adhesion signaling, receptor-mediated internalization, motility, transformation, invasion, and transcription. ${ }^{13,14}$ RhoB is inducible by DNA-damaging agents, such as UV radiation. ${ }^{15}$ In contrast to other Rho proteins which are solely geranylgeranylated, RhoB is present in both a farnesylated and a geranylgeranylated form in vivo. ${ }^{16,17}$ Previous data have 
suggested that this protein might be a potential target of the antitumoral effects of FTIs. ${ }^{13,18}$ Moreover, the role of RhoB in cell death mechanisms, and more precisely in apoptosis regulation, has been widely reported in fibroblasts and epithelial cells. ${ }^{19,20}$ We demonstrated earlier that expression of the dominant negative form of RhoB, RhoBN19, in FGF-2expressing HeLa cells ${ }^{21}$ or in radioresistant U87 human glioma ${ }^{7}$ dramatically reduced cell survival following irradiation of these two cell lines, but this effect was also apparent in U87 xenografts, $^{22}$ as previously shown using FTIs. ${ }^{6,7}$ Furthermore, inhibiting $\mathrm{RhoB}$ in these radioresistant cell lines increased the percentage of cells undergoing mitotic cell death. ${ }^{6,7}$ Taken together, these data strongly suggest that the farnesylated form of RhoB may well be at least one of the farnesylated proteins that regulate radiation-induced mitotic cell death.

The aim of this work was to determine whether RhoB and, more specifically the farnesylated form of the protein, controls nonapoptotic radiation-induced cell death mechanisms. In the present paper, we demonstrate that expression of a farnesylated, but not a geranylgeranylated form, of RhoB protects radiosensitive cells from radiation-induced mitotic cell death. We then investigated the impact of farnesylated RhoB expression on radiation-induced G2/M arrest, centrosome overduplication and the role of the downstream effectors of Rho on such regulatory events.

\section{Results}

\section{Expression of RhoB but not of RhoA inhibits radiation-induced mitotic cell death}

We have previously shown that the constitutive expression of V14RhoB, but not V14RhoA, in radiosensitive NIH3T3 cells dramatically increases survival following irradiation of these radiosensitive cells. ${ }^{21}$ So we went on to investigate which type of radiation-induced cell death can be prevented in NIH3T3 cells by RhoB expression. No significant induction of apoptosis was detected within 6 days following irradiation of RhoB-transfected clones or of the radiosensitive control cells (data not shown). However, the appearance of giant multinucleated cell, characteristic of cells undergoing mitotic cell death, was observed in the radiosensitive Mock- or RhoAtransfected cells (Figure 1a). We examined the viability of these giant multinucleated cells by analyzing propidium iodide (PI) permeability of these cells. Cells became permeable to $\mathrm{PI}$ without any DNA fragmentation, indicating that the giant multinucleated cells underwent necrosis (Figure 1b). We then quantified the percentage of these cells in the different clones after their irradiation (Figure 1c). While expressing RhoA in NIH3T3 cells did not significantly modify the number of cells undergoing mitotic cell death, the percentage of giant multinucleated cells was significantly lower in RhoB-expressing cells. Similar results have been obtained in cells expressing wild-type RhoB (data not shown). These data therefore demonstrate that the expression of $\mathrm{RhoB}$ in radiosensitive NIH3T3 cells inhibits radiation-induced nonapoptotic cell death and, more specifically, mitotic cell death.
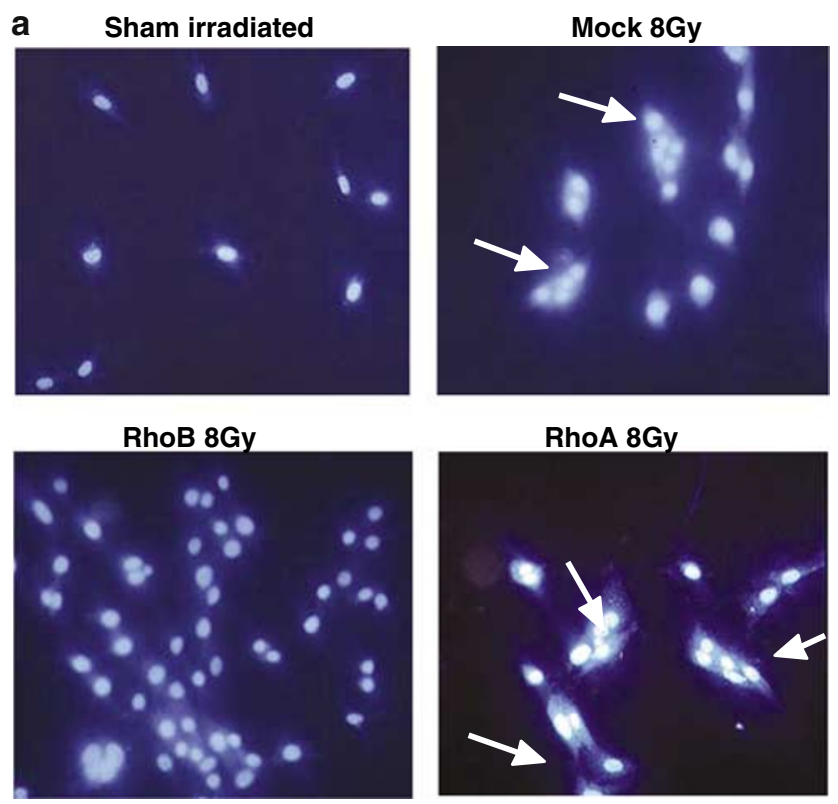

b
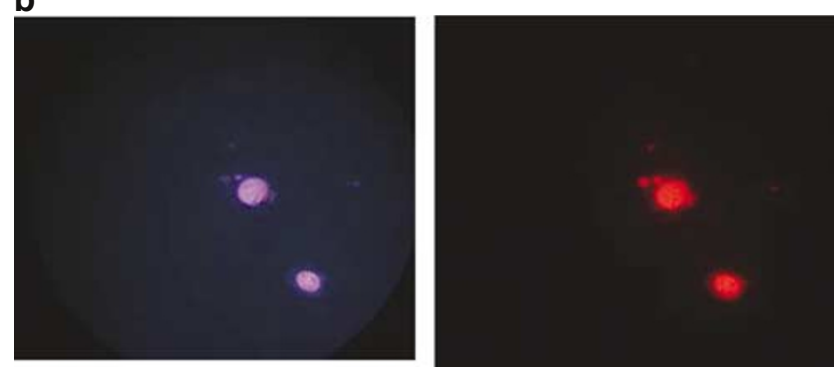

C

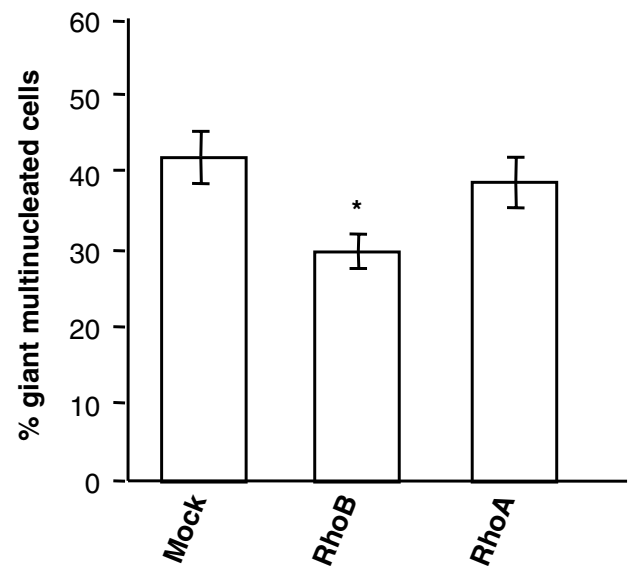

Figure 1 RhoB, but not RhoA, protects $\mathrm{NIH} 3 \mathrm{~T} 3$ cells from radiation-induced nonapoptotic cell death. (a) NIH3T3 cells were transfected with the empty vector (Mock), with the cDNA encoding for RhoB (RhoB cells), or with RhoA (RhoA cells). DAPI staining was performed at $144 \mathrm{~h}$ for sham-irradiated cells or after exposure to 8 Gy irradiation. Arrows indicate giant multinucleated cells. (b) DAPI (left panel) and propidium iodide (right panel) stainings were performed at $144 \mathrm{~h}$ after exposure to $8 \mathrm{~Gy}$ irradiation. (c) Giant multinucleated cells were quantified by determining the number in 100 cell fields after exposure to $8 \mathrm{~Gy}$ irradiation. Data represent the mean of at least three different experiments. Bars: S.D. Star: The percentage of giant multinucleated in RhoB cells is significantly lower than that of the Mock or RhoA cells $(P<0.001)$ 


\section{Farnesylated RhoB inhibits radiation-induced mitotic cell death}

We have previously demonstrated that FTI treatment stimulates the appearance of giant multinucleated cells after irradiation $^{6,7}$ and that this effect was mimicked by inhibiting RhoB pathways; ${ }^{21}$ therefore, we now postulated that the two prenylated forms of RhoB might not have the same radioprotective effect and, in consequence, the same impact on radiation-induced mitotic cell death mechanisms. To investigate this aspect, we used NIH3T3 cells encoding for RhoB mutants that had been mutated to produce specific prenylation, either CAIM for farnesylation (RhoB-F cells) or CLLL for geranylgeranylation (RhoB-GG cells), or a CAAX deletion mutant that did not permit RhoB prenylation (RhoB-D cells) as well as wild-type CAAX (RhoB cells), as described previously ${ }^{17,24}$ (Figure 2a). We first determined the SF2 value of different clones for each construction (Figure 2b). In these NIH3T3 cells, resistance to ionizing radiation was affected neither by the constitutive expression of RhoB-D nor by RhoBGG. In contrast, RhoB-F cells exhibited a significantly increased SF2 value relative to that of the control cells $(P<0.001)$ (Figure 2b). These results provide the first demonstration that the nature of the prenyl group was crucial

a
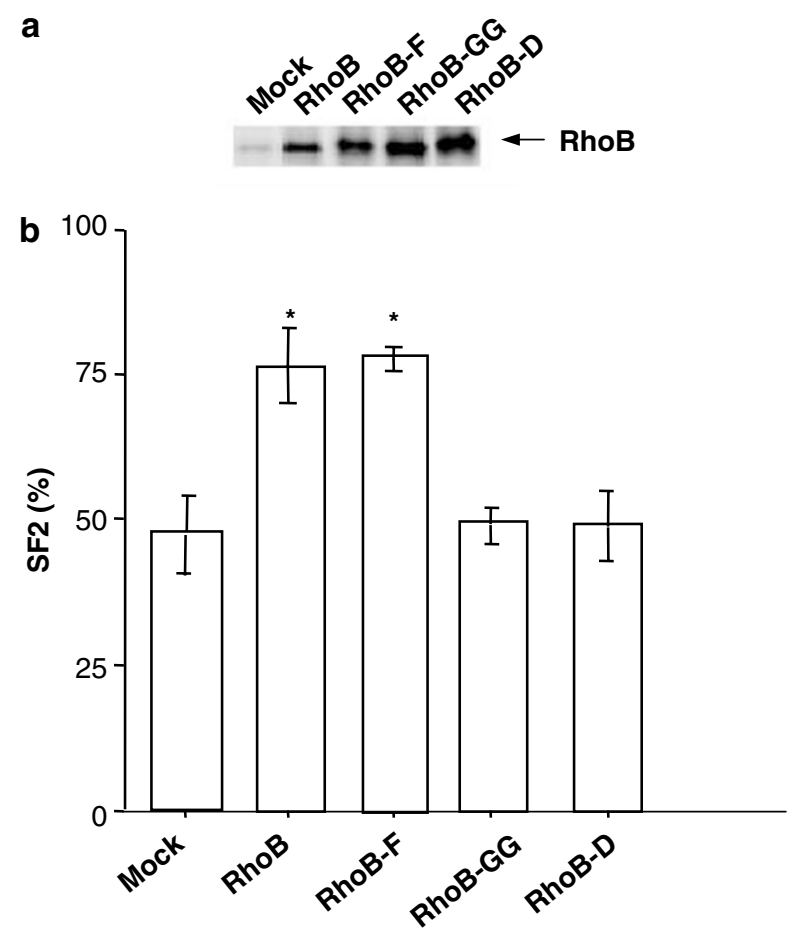

Figure 2 RhoB-F but not RhoB-GG cells showed an increased resistance to ionizing radiation. (a) NIH3T3 cells were transfected with the empty vector (Mock) or with the CDNA encoding for nonmutated CAAX RhoB (RhoB cells), farnesylated RhoB (RhoB-F cells), geranylgeranylated RhoB (RhoB-GG cells), or the deleted CAAX box RhoB (RhoB-D cells). RhoB mutant expression was checked for the various clones obtained by Western blotting. Data presented are representative of at least three different experiments. (b) Radioresistance of the obtained clones obtained was determined by quantifying the SF2 values, as described in Materials and Methods. Data represent the mean of at least three different experiments. Bars: S.D. Star: The SF2 values of RhoB- and RhoB-Ftransfected cells are significantly different from those of Mock, or RhoB-GG or RhoB-D cells $(P<0.001)$ for acquisition of radioresistance and that expression of RhoB-F, but not of RhoB-GG, induced a radioprotective effect in NIH3T3 cells.

We then examined whether treating NIH3T3 cells with the specific FTI, R115777, could reverse this RhoB-F-induced radioresistance. Cells transfected with $\mathrm{RhoB}-\mathrm{F}$ were treated with R115777 at $1 \mathrm{nM}$ and the inhibition of RhoB-F farnesylation was checked by immunoprecipitation of the farnesylated proteins with the selective antifarnesylated cysteine antibody we described previously. ${ }^{17}$ No signal was detected after treatment with either $20 \mu \mathrm{M}$ lovastatin or with $1 \mathrm{nM}$ R115777 treatment (Figure 3a upper gel), although at the same time no significant difference in RhoB expression was observed (Figure 3a lower gel). This finding indicated that an inhibition of RhoB- $F$ farnesylation occurred after treatment with $1 \mathrm{nM}$ R115777. Under these treatment conditions, cell growth of the various NIH3T3 clones was unaffected (data not shown). In addition, neither the SF2 value of empty vector transfected cells nor of RhoB-D cells was modified by this treatment with R115777 (Figrue 3b). In contrast, a dramatically decrease in the SF2 value was observed on treating RhoB cells containing both prenylated forms of RhoB in vivo with R115777. The same radiosensitizing effect of this FTI was obtained with RhoB-F, but not with RhoB-GG cells (Figure $3 b$ ). This demonstrated that the radioprotective effect induced by $R$ hoB expression in NIH3T3 cells was only associated with the farnesylated form of the protein.

We then investigated the impact on radiation-induced cell death of expressing the two prenylated forms of RhoB. As previously observed when expressing $\mathrm{RhoB}$, no significant induction of apoptosis was detected within $144 \mathrm{~h}$ following irradiation in any of the various RhoB mutant transfected clones (data not shown). Then the number of giant multinucleated cells identified during the $144 \mathrm{~h}$ post irradiation was then quantified in the various clones (Figure $3 c$ ). This percentage of giant multinucleated cells was significantly lower for RhoB-F cells $(P<0.001)$ than for the RhoB-GG cells. This finding has demonstrated the protection conferred by RhoB-F on NIH3T3 cells from radiation-induced lethality by inhibiting radiation-induced mitotic cell death.

\section{RhoB-F cells displayed an increased G2 arrest following irradiation}

Radiation-induced G2/M arrest has been largely implicated in the resistance of cells to ionizing radiation. ${ }^{26,27}$ Furthermore, it has been largely reported that this G2 checkpoint is particularly important in preventing mitotic catastrophe in cells exposed to DNA damage (for a review, See Roninson et $a I^{8}{ }^{8}$. We therefore compared the effect of expressing either RhoB-F or RhoB-GG on radiation-induced G2/M arrest. No difference in cell cycle distribution has been observed between unirradiated RhoB-F and RhoB-GG cells (data not shown). In contrast, both RhoB-F- and RhoB-GG-expressing cells entered a $\mathrm{G} 2 / \mathrm{M}$ block within $5 \mathrm{~h}$ of their exposure to irradiation ( $8 \mathrm{~Gy}$ ). The radioresistant RhoB and RhoB-F cells showed an increase in the extent of this block ( $52 \%$ for RhoB cells versus only $18 \%$ for RhoB-GG cells $15 \mathrm{~h}$ after irradiation) (Figure 4a). The duration of this radiation-induced G2/M arrest was also more extended for RhoB-F cells than for RhoB-GG 
a
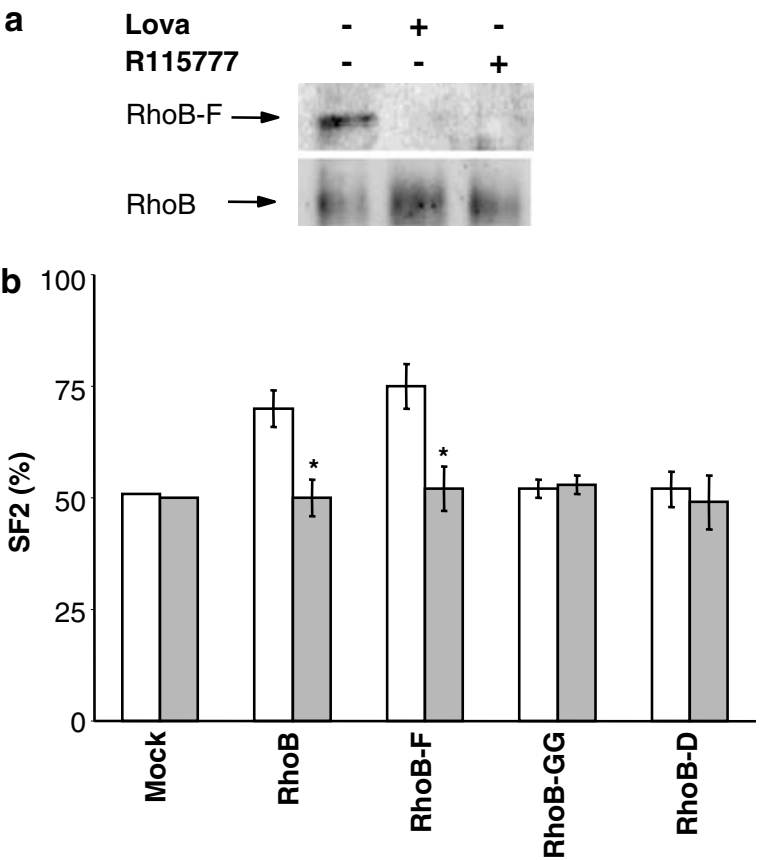

C

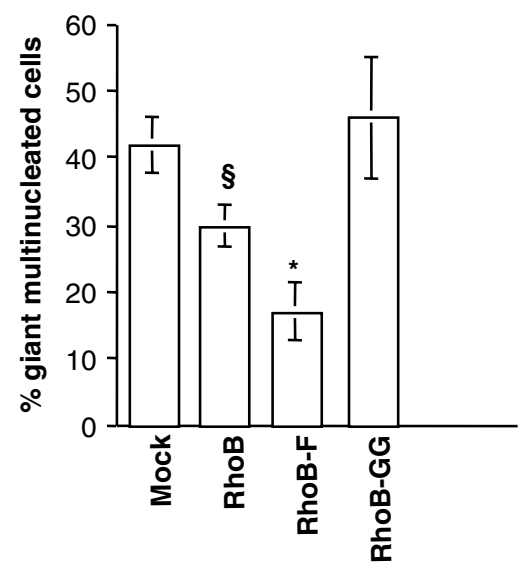

Figure 3 RhoB-F protects NIH3T3 cells against radiation-induced mitotic cell death. (a) Specific immunoprecipitation of the farnesylated form of RhoB was performed after a 48-h treatment with either $1 \mathrm{nM}$ R115777, $20 \mu \mathrm{M}$ lovastatine (lova) or vehicle alone using the antifarnesylated cysteine antibody and analysis by Western blotting probed with a rabbit anti-RhoB antibody, as described in Materials and Methods (upper gel). A Western blot was performed at the same time to check that the FTI treatment did not affect RhoB expression (lower gel). (b) Radioresistance of the different clones was determined by quantifying the SF2 value after a 48-h treatment with either $1 \mathrm{nM}$ R115777 (gray bars) or vehicle (white bars), as described in Materials and Methods. Data represent the mean of at least three different experiments. Bars: S.D. (S.D. representing less than $1 \%$ of variation are not included for clarity). Star: SF2 values of RhoB-F and RhoB cells are significantly lower after the FTI treatment than that of untreated cells $(P<0.02)$. (c) Giant multinucleated cells were quantified by determining the number in 100 cell fields after exposure to $8 \mathrm{~Gy}$ irradiation. Data represent the mean of at least three different experiments. Bars: S.D. Star: The percentage of giant multinucleated in RhoB-F cells is significantly lower than in the Mock or the RhoB-GG cells $(P<0.001)$. ${ }^{\text {TT }}$ The percentage of giant multinucleated RhoB cells is significantly lower than those either of Mock or RhoB-GG cells $(P<0.01)$

cells (14 versus $7 \mathrm{~h}$ ). To determine if this delay was due to a G2 or mitosis arrest, we determined the percentage of mitotic cells by flow cytometry assessment of histone $\mathrm{H} 3$ phosphorylation after irradiation (Figure $4 b$ and $c$ ). The number of cells in mitosis of irradiated cells was not significantly different from the one of sham-irradiated cells $(2.02 \pm 0.76 \%$ of mitotic cells for sham-irradiated RhoB-F cells compared to $3.05 \pm 0.46 \%$ $16 \mathrm{~h}$ after irradiation), indicating that these cells were not blocked in mitosis after irradiation. Taken together, these results demonstrated that expressing $\mathrm{RhoB}-\mathrm{F}$ in radiosensitive NIH3T3 cells regulated the G2 arrest after irradiation.

\section{RhoB-F inhibited radiation-induced centrosomal defects}

The mechanisms controlling radiation-induced mitotic cell death are, as yet, poorly defined. Recently, it has been shown that this type of cell death is a consequence of the regulation of radiation-induced centrosomal overduplication.,10 To determine whether RhoB-F expression might modify the centrosome cycle, we labelled interphase-irradiated cells from the different clones with anti- $\gamma$ tubulin antibody. Shamirradiated NIH3T3 cells displayed one or two centrosomes (Figure 5a left panel), but, following irradiation, these radiosensitive cells were found to contain supernumerary centrosomes (Figure 5a right panel). These supernumerary centrosomes could be either clustered together or dispersed throughout the cell (Figure 5a). We then quantified the number of cells in the various RhoB cell lines containing more than two centrosomes $24 \mathrm{~h}$ after irradiation (Figure $5 \mathrm{~b}$ ). The percentage of cells containing supernumerary centrosomes was lower in RhoB-F-expressing cells than in radiosensitive ones (7.1 $\pm 1.8 \%$ for RhoB-F-expressing cells versus $21.4 \pm 3.36 \%$ for RhoB-GG-transfected cells; $P<0.01$ ), demonstrating that RhoB-F-expression inhibited the radiation-induced appearance of supernumerary centrosomes. Among the radioresistant cell population with supernumerary centrosomes, we then determined the percentage containing clustered supernumerary centrosomes. In the RhoB-F-expressing cells with supernumerary centrosomes, $70 \pm 6.4 \%$ contained clustered centrosomes, while only $52.2 \pm 3.3 \%$ of the radiosensitive RhoB-GG-expressing cells showed the same $\gamma$-tubulin labelling $(P<0.02)$. This observation indicated that RhoB-F expression might also influence the position of the supernumerary centrosomes within the cells. Overall, our results have demonstrated that RhoB-F expression inhibited radiation-induced centrosome overduplication.

\section{RhoB-F inhibits radiation-induced mitotic cell death and centrosome overduplication via Rho kinase}

To elucidate the mechanisms underlying the differential effects of the two prenylated forms of RhoB, we then examined the subcellular localization of these proteins when transfected into NIH3T3 cells. Recent works of Wherlock ${ }^{28}$ has demonstrated that, in HeLa cells, RhoB is localized in the plasma membrane and vesicles. FTI treatment of these cells caused a loss of RhoB plasma membrane staining, suggesting that RhoB-F may be localized to the plasma membrane, while RhoB-GG resides in the endocytic compartment. In our hands, overexpressing RhoB in NIH3T3 cells induced a plasma membrane and a punctate intracellular staining pattern (Figure 6). However, when expressed in NIH3T3, 
a

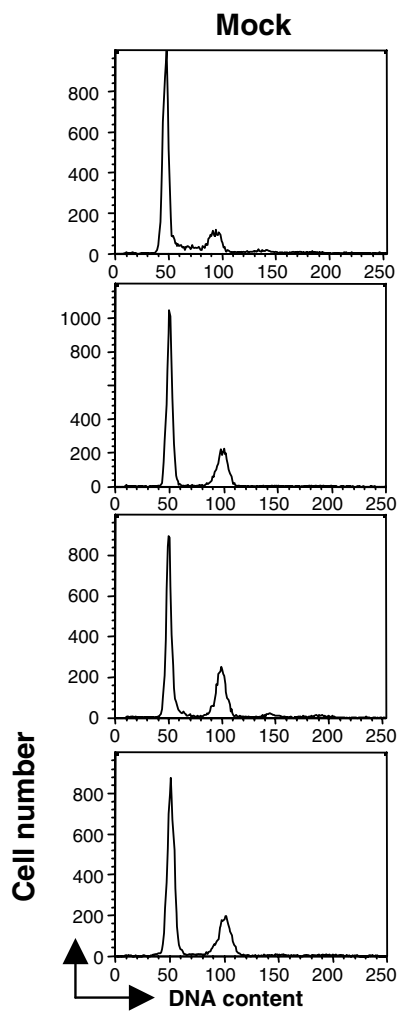

b

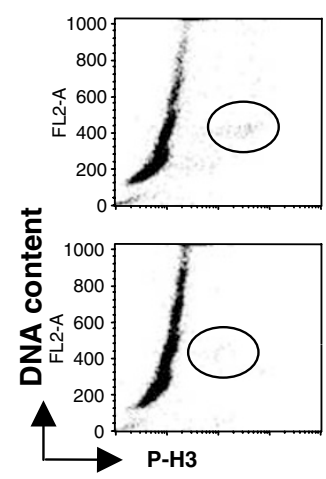

RhoB-F
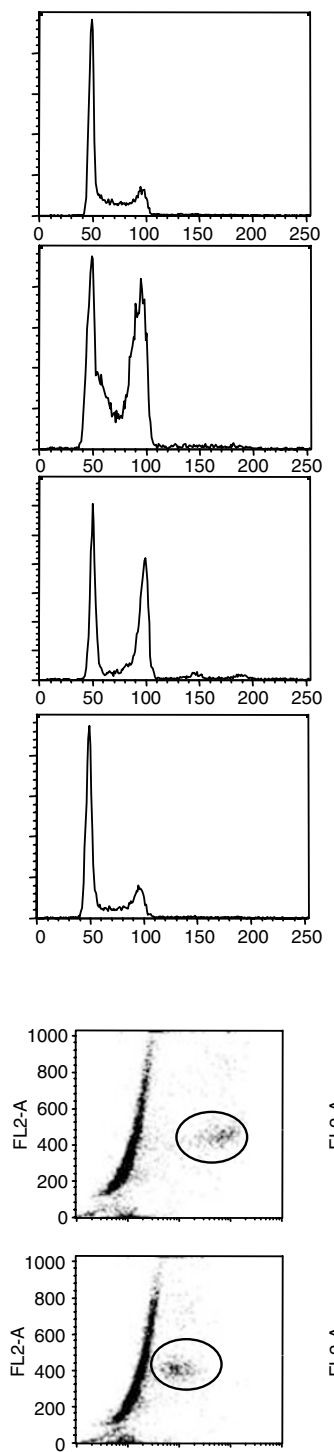

RhoB-GG
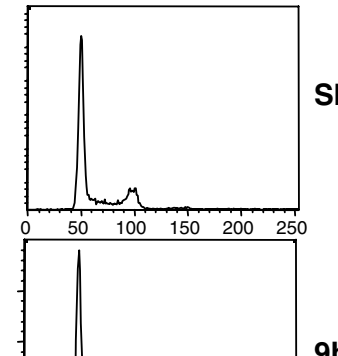

$9 \mathrm{~h}$

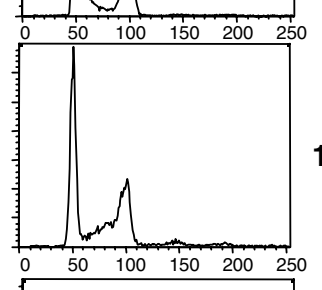

$15 h$

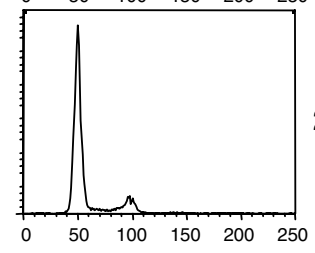

24h

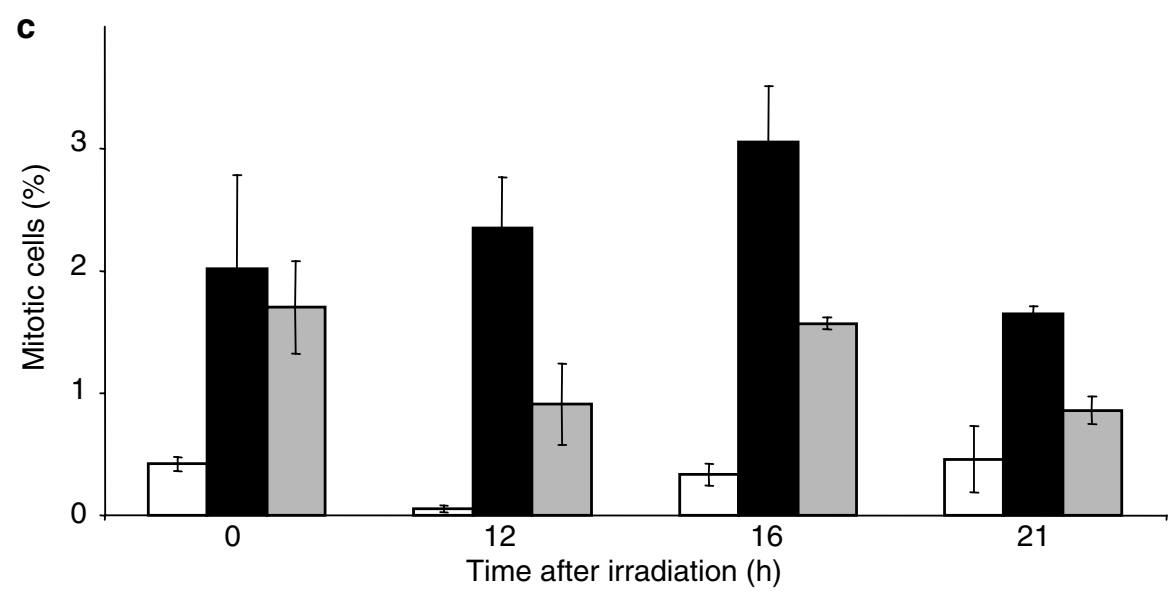



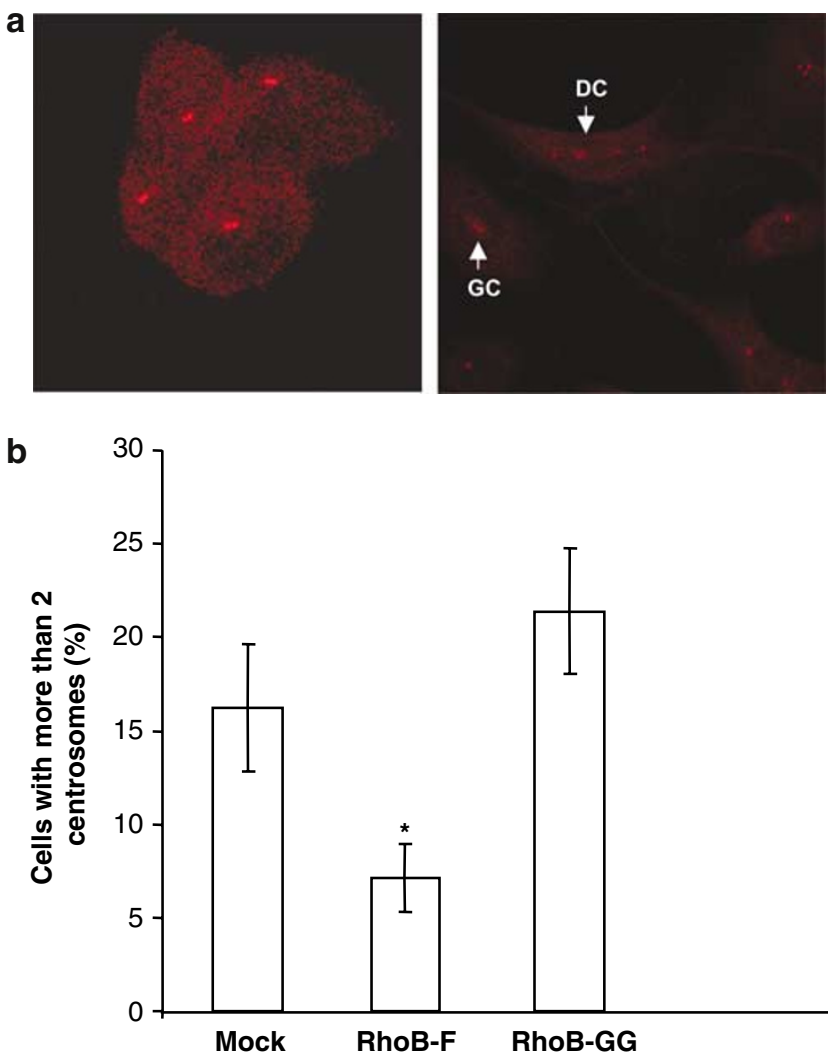

Figure 5 lonizing radiation induced centrosomal defects in $\mathrm{NIH} 3 \mathrm{~T} 3$ cells. (a) Radiosensitive cells were sham irradiated (left panel) or exposed to $8 \mathrm{~Gy}$ irradiation (right panel) and then stained with an anti- $\gamma$-tubulin antibody, as described in Materials and Methods. Arrows indicate the centrosomal abnormalities. After irradiation, supernumerary centrosomes can be either clustered (GC) or dispersed in the cell (DC). (b) The percentage of cells in the different clones containing more than two centrosomes was determined by immunocytochemistry $24 \mathrm{~h}$ after exposure to 8 Gy irradiation, as described in Material and Methods. Bars: S.D. Star: The percentage of cells containing more than two centrosomes is significantly higher in both Mock and RhoB-GG cells than in RhoB-F cells $(P<0.01)$

RhoB-F is clearly localized at the plasma membrane. This finding indicates that RhoB-F appears to interact with specific downstream effectors so as to activate a specific signalling pathway from the membrane, resulting in an inhibition of radiation-induced centrosomal overduplication and mitotic cell death. Among the known downstream effectors of Rho proteins, Rho kinases might be potential candidates for mediating RhoB-F effect on centrosome overduplication and mitotic cell death. Rho kinases have been localized at the cell membrane,$^{29}$ at the cleavage furrow in late mitosis, ${ }^{30}$ and, more recently, for p160ROCK in centrosomes. ${ }^{31}$ Furthermore, p160ROCK is required for centrosomal positioning and centrosome-dependent exit from mitosis. ${ }^{31}$ In order to determine whether ROCK might mediate the RhoB-F radio-
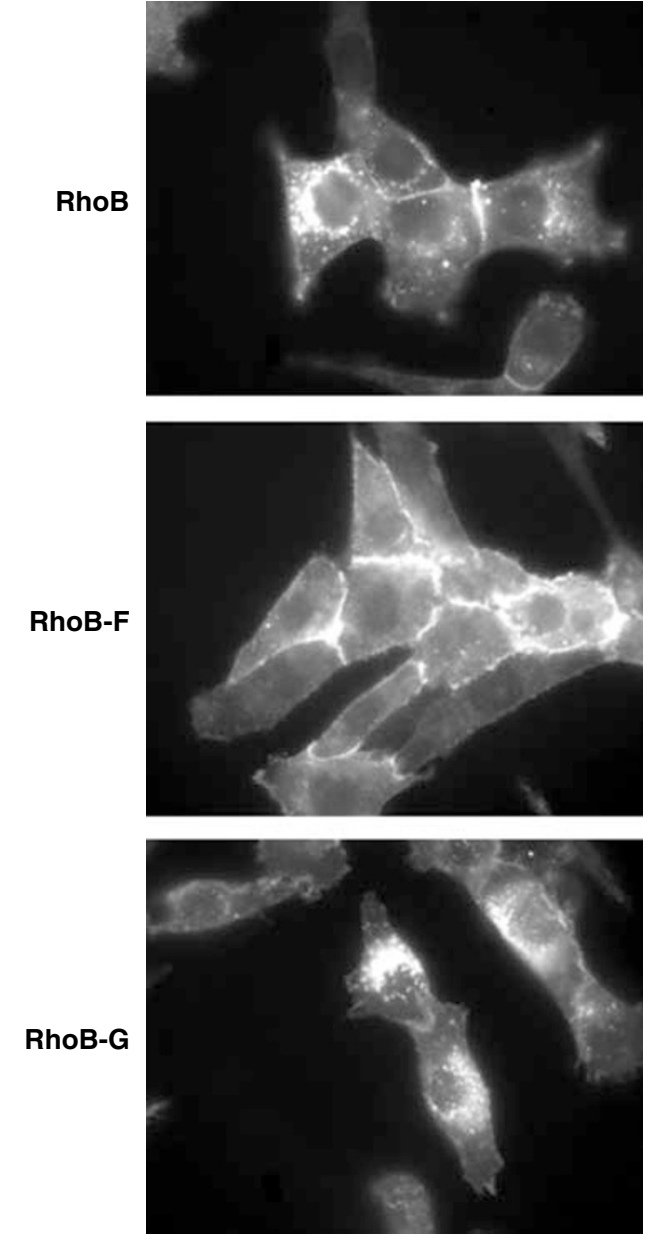

Figure 6 Cellular localisation of the two prenylated form of RhoB. RhoB, RhoB$F$, and RhoB-GG cells were then stained with anti-RhoB antibody. Cells on coverslips were fixed with $4 \%$ paraformaldehyde before the application of the mouse anti-RhoB (Santa-Cruz) $1 / 50$ in PBS $10 \%$ FCS at $4{ }^{\circ} \mathrm{C}$ overnight. Cells were then incubated with FITC mouse antibodies (Sigma) at 1/200 and analyzed using Zeiss fluorescent microscope as described in Materials and Methods

protective effect, we treated RhoB-F and RhoB-GG cells with the ROCK inhibitor Y27632, ${ }^{32}$ prior to irradiation, and quantified the number of giant multinucleated cells $144 \mathrm{~h}$ after irradiation (Figure 7a). Treatment of RhoB-GG-expressing or Mock-transfected cells with this inhibitor has no effect on the number of giant multinucleated cells evident after irradiation. However, treatment of RhoB-F cells with Y27632 prior to irradiation significantly increases the cell death via mitotic cell death mechanisms (Figure 7a). We then examined whether the centrosome cycle might be affected by this treatment prior to irradiation. As shown in Figure 7b, while Y27632 had no effect on the proportion of Mock or RhoB-GG cells containing more than two centrosomes $24 \mathrm{~h}$ after irradiation, it dramatically increased the percentage of RhoB-F cells presenting

Figure 4 RhoB-F expression increased radiation-induced G2 arrest. (a) FACS analysis of the DNA content of Mock, RhoB-F and RhoB-GG cells were performed for sham-irradiated cells (SI) or at various times after irradiation ( $8 \mathrm{~Gy}$ ), as described in Materials and Methods. Data are representative of three different experiments. (b) Mock, RhoB-F, and RhoB-GG cells were sham irradiated (SI) or irradiated with $8 \mathrm{~Gy}$ and mitotic index was determined using phospho-H3 labelling by flow cytometry, after irradiation as described in Materials and Methods. (c) Histograms representing the percentage of phospho-H3-positive Mock (white bars), RhoB-F (black bars), and RhoB-GG (gray bars) cells. Time 0 represents the mitotic index of the sham-irradiated cells. Data represent the mean of three different experiments. Bars: S.D. 

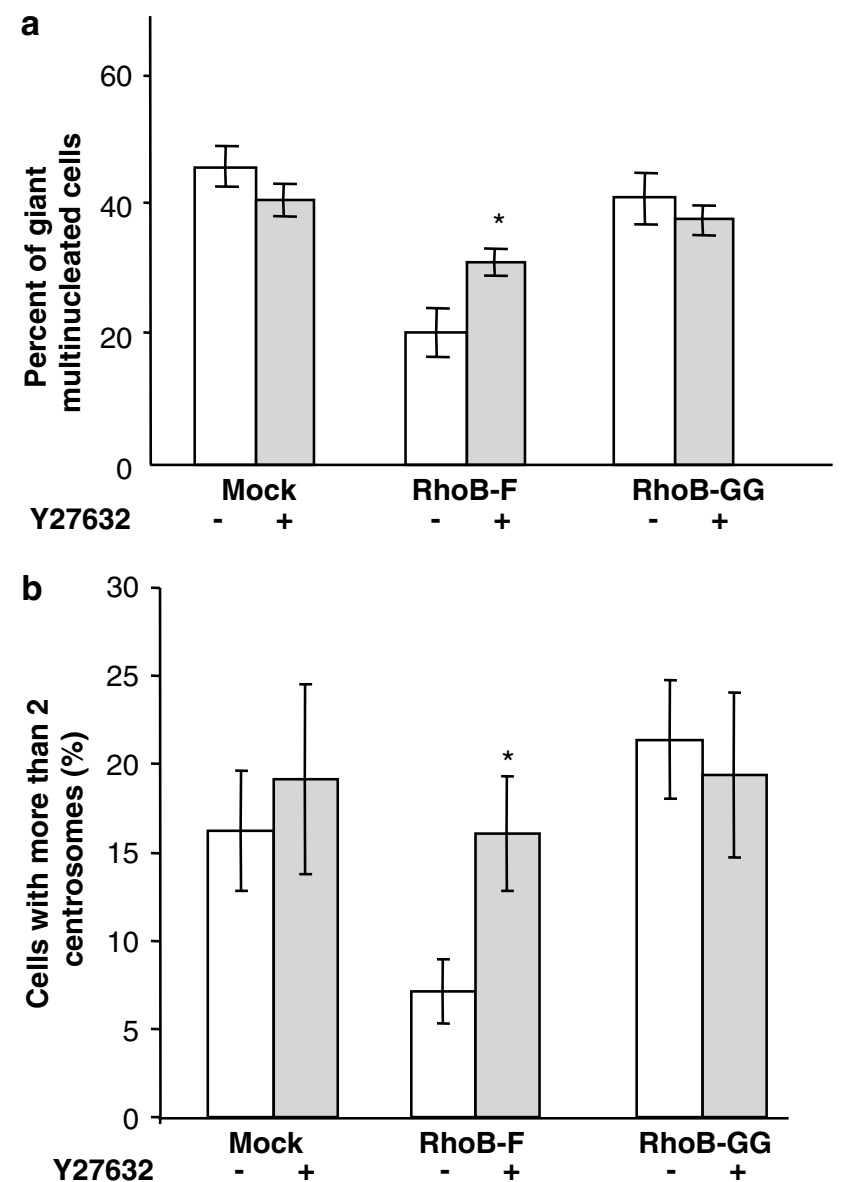

Figure 7 Inhibiting Rho kinase reverses the inhibition of radiation-induced mitotic cell death by RhoB-F. (a) Giant multinucleated cells were quantified by determining the number in 100 cell fields 6 days after exposure to 8Gy irradiation of cells treated either with Y27632 (gray bars) or with vehicle (white bars). Data represent the mean of at least three different experiments. Bars: S.D. Star: The percentage of giant multinucleated cells is significantly higher in RhoB-F cells after treatment with Y27632 $(P<0.05)$. (b) The percentage of cells containing more than two centrosomes was determined by immunohistochemistry $24 \mathrm{~h}$ after the exposure of $8 \mathrm{~Gy}$ irradiation of cells treated $30 \mathrm{~min}$ prior to irradiation either with Y27632 $10 \mu \mathrm{M}$ (gray bars) or with vehicle (white bars) as described in Materials and Methods. Bars: S.D. Star: The percentage of cells containing more than two centrosomes is significantly higher in RhoB-F-expressing cells after Y27632 treatment $(P<0.02)$

supernumerary centrosomes. These results strongly suggest that inhibiting ROCK leads to the activation of mitotic cell death mechanisms via the control of radiation-induced centrosomal overduplication in RhoB-F-expressing cells. Taken together, our results showed that RhoB-F expression regulates the G2 delay after irradiation, inhibits radiationinduced centrosomal overduplication, and, in turn, mitotic cell death by a signalling pathway activated from the plasma membrane probably via Rho kinases.

\section{Discussion}

We have shown here that, when expressed in radiosensitive NIH3T3 cells, the radioprotective effect of RhoB is due to its farnesylated form that inhibits radiation-induced cell death mechanisms. Ionizing radiation can induce apoptotic or mitotic cell death. The involvement of RhoB in apoptosis has already been described in cancer cells ${ }^{20}$ or in cells exposed to DNA-damaging agents. In particular, Liu et al. ${ }^{19}$ have demonstrated that, in $\mathrm{E} 1 \mathrm{~A}$ transformed mouse embryo fibroblasts (MEF), RhoB loss was associated with resistance to DNA-damage-induced apoptosis. Our previous works has suggested a role for this protein in radiation-induced mitotic cell death. Indeed, inhibiting RhoB pathways induced mitotic cell death activation in several cell lines including glioblastoma, ${ }^{7} \mathrm{HeLa}^{21}$ and the A549 lung adenocarcinoma (Ader, unpublished results). Our present work clearly demonstrates an inhibitory role for the farnesylated form of RhoB in radiation-induced mitotic cell death mechanisms in radiosensitive cell lines. This strongly suggests that RhoB and, more specifically, the farnesylated form of the protein may act as surviving factor by controlling different cell death mechanisms.

Published data have highlighted the particular importance of the G2 checkpoint in preventing mitotic catastrophe in cells treated with DNA-damaging agents. ${ }^{8}$ Moreover, the relationship between radiation-induced G2/M delay and the cellular response to ionizing radiation has been studied extensively. ${ }^{27,33,34}$ While examining the mechanisms of this survival effect of RhoB-F, we have further demonstrated that radioresistant $R$ hoB-F cells exhibited a more marked G2/M arrest than RhoB-GG cells, strongly implicating RhoB-F in the control of mechanisms of mitotic entry or the mitotic checkpoint following irradiation. We then showed that this RhoB-F-induced G2/M delay after irradiation was not due to a delay in mitosis, but due to a protracted G2 delay. The appearance of mitotic cell death has recently been related to an abnormality of centrosomal duplication during the cell cycle after irradiation. ${ }^{9,10}$ The centrosomes that are the major microtubule-organizing center (MTOC) of mammalian cells, are not only key regulators in building the mitotic spindle that pulls duplicated chromosomes apart during cell division, but also they actively participate in the control of microtubule nucleation, cell cycle progression, and the stress response, as well as cell cycle checkpoint control. All these processes need to function harmoniously to control the fidelity of cell division. ${ }^{35}$ Centrosome abnormalities have been described extensively in several types of cancer and have often been associated with their chromosomal abnormalities. ${ }^{36-39}$ Centrosome duplication begins near the G1/S transition and completes during the G2 phase. However, it has been very recently shown that radiation-induced centrosome amplification occurs during an extended G2 phase and that, instead of being an aberrant phenomenon, this amplification may offer a means to ensure the deletion of cells with DNA damage. ${ }^{40}$ While investigating a potential role for RhoB-F in centrosome duplication regulation, our results showed that irradiation of radiosensitive cells resulted in the appearance of supernumerary centrosomes since $9 \mathrm{~h}$ after irradiation while cells are in G2 phase (data not shown). RhoB-F expression clearly decreased the percentage of cells containing these abnormal centrosomes within the $24 \mathrm{~h}$ following their irradiation. The presence of these supernumerary centrosomes could be explained either by successive abortive cytokinesis or by an 
overduplication of the centrosomes induced by irradiation. However, following irradiation, these radiosensitive cells that normally duplicate within $18 \mathrm{~h}$ are in fact arrested in G2 and so could not possibly undergo several mitoses within a $24 \mathrm{~h}$ period following irradiation. This observation, therefore, suggested that the farnesylated form of RhoB inhibits the radiation-induced overduplication of the centrosomes possibly during the $\mathrm{G} 2$ delay.

Furthermore, among the RhoB-F-expressing cells containing more than two centrosomes, localization of these supernumerary centrosomes was not identical to that observed in irradiated RhoB-GG cells. While radioresistant cells mainly presented centrosomes clustered in a particular area of the cell, radiosensitive cells contain extra-centrosomes dispersed throughout the cell. The presence of giant centrosomes in tumor cells has been reported in several publications and it has been suggested that these multiple centrosomes might cluster into one large aggregate, so reducing the number of MTOC to a manageable one or two per cell. Such an arrangement would favor mitotic stability and neoplastic growth (for a review, see Brinkley ${ }^{41}$ ). In our experiments, the multi-centrosomes contained in irradiated RhoB-F cells were unable to randomly migrate within the cell. This result suggests that RhoB-F may influence the position of the supernumerary centrosomes within the cell and, just as in cancer cells, this arrangement could favor survival after irradiation. Further work is underway, aimed at determining which pathways implicated in centrosome duplication following irradiation are actually under the control of RhoB-F.

To understand how RhoB-F, but not RhoB-GG, could regulate this radiation-induced centrosomal overduplication, we then went on to show that, while RhoB-GG is localized to the endocytic compartment, RhoB- $F$ was located in the cellular membrane. This indicates that RhoB-F triggers a signalling pathway from the membrane that is able to control radiation-induced centrosomal overduplication and in turn mitotic cell death in radiosensitive cells. To further dissect the biological pathway controls operating by RhoB-F, which lead to the regulation of the centrosomal cycle after irradiation, we then determined which downstream effector of Rho might mediate the specific radioprotective effect of RhoB-F. The protein serine/threonine kinases Rho-kinases (or ROCK) are downstream effectors of Rho able to selectively interact with the GTP-bound form of Rho. Moreover, it has recently been demonstrated that p160ROCK is a centrosome component, which functions in centrosome positioning ${ }^{31}$ and also with Aurora A controls progression through $\mathrm{G} 2 / \mathrm{M},{ }^{42}$ which suggest that this protein may mediate the radioprotective effect of RhoB-F. We have shown that treatment of RhoB-F-expressing cells with the ROCK inhibitor, Y27632, activated mitotic cell death mechanisms and centrosome overduplication after irradiation. The same treatment though has no effect on RhoB-GG cells. This strongly suggests that ROCK mediates the effect of RhoB-F on centrosomal duplication; and thus in consequence, mitotic cell death after irradiation, and may implicate the involvement of these proteins, already involved in apoptosis regulation (for a review, see Riento and Ridley ${ }^{43}$ ) in another type of cell death after irradiation.

Taken together, our present results have demonstrated, for the first time, that mitotic cell death, the most significant cell death in tumors exposed to irradiation, is controlled by the farnesylated form of the small GTPase. These findings reinforce the idea that $\mathrm{RhoB}$ plays a key role in the cellular mechanism(s) of survival after irradiation and its further elucidation could lead to new insights into radiation-induced cancer cell mechanisms, which might prove therapeutically exploitable.

\section{Materials and Methods}

\section{Reagents, antibodies and plasmids}

Dulbecco's modified Eagle's medium (DMEM), calf serum, and all other culture reagents were purchased from In vitrogen (Cergy Pontoise, France). Zeocine was obtained from Cayla (Toulouse, France). The FTI R115777 (a gift from Dr. D End, Johnson and Johnson Pharmaceutical Research and Development, Spring House, PA, USA) was dissolved in DMSO. ${ }^{23}$ The ROCK inhibitor Y27632 was purchased from Calbiochem. Horseradish peroxidase-labelled goat anti-rabbit $\lg G$ and fluorescein isothiocyanate-conjugated anti-mouse immunoglobulinG antibody were, respectively, obtained from Biorad (Ivry/Seine, France) and DakoCytomation (Dako, France); rabbit polyclonal anti-RhoB from Santa-Cruz Biotechnology Inc. (Santa-Cruz, CA, USA), anti-phosphorylated histone (phospho-H3) (6G3) from Cell Signalling (Cell Signalling Technology, USA). The rabbit F-Cys $\mathrm{Ab}$ was produced in this laboratory. ${ }^{17}$ Nitrocellulose and nonfat-dried milk protein were obtained from Biorad (Ivry/Seine, France). The ECL system and Hyperfilm MP were purchased from Amersham (les Ulis, France). Cells were irradiated with a clinical Cobalt 60 machine (Theratronics 1000, AECL, Ottawa, Canada).

Standard PCR reaction mutagenesis was used to generate pCMV plasmids encoding for constitutively active $\mathrm{V} 14 \mathrm{RhoB}(\mathrm{RhoB})$ or the wildtype RhoB, with a farnesylated (RhoB-F), a geranylgeranylated (RhoB-GG) CAAX sequence or with the CAAX-deleted sequence (RhoB-D), as described previously. ${ }^{17} \mathrm{NIH} 3 \mathrm{~T} 3$ cells were transfected with these various mutants to obtain either RhoB-F- (RhoB-F cells), RhoB-GG- (RhoB-GG cells), RhoB-D- (RhoB-D cells), or wild-type CAAX box RhoB- (RhoB cells) expressing cells.

\section{Cell culture and transfection}

Cells were maintained in DMEM supplemented with $10 \%$ calf serum at $37^{\circ} \mathrm{C}$ in $5 \% \mathrm{CO}_{2}$-humidified incubators and subcultured weekly.

pCMV $(10 \mu \mathrm{g})$ carrying the CDNA encoding for the different RhoB were transfected into NIH3T3 cells using Lipofectamin (Gibco, France), according to the manufacturer's instructions. Selection was initiated $48 \mathrm{~h}$ later by incubating cells in fresh medium containing zeocine so as to obtain expressing clones, as described previously. ${ }^{24}$

\section{Western blotting analysis}

Cells were harvested from monolayer cultures by rinsing twice with cold phosphate-buffered saline (PBS), followed by scraping with a rubber policeman. Cells were centrifuged at $400 \times g$ for $10 \mathrm{~min}$ at $4^{\circ} \mathrm{C}$ and then lysed in ice-cold $50 \mathrm{mM}$ Tris, $\mathrm{pH}$ 8, $1 \mathrm{mM}$ EDTA, $250 \mathrm{mM} \mathrm{NaCl}, 0.5 \%(\mathrm{v} / \mathrm{v})$ Triton X-100, $10 \mathrm{mM}$ sodium orthovanadate, $50 \mathrm{mM}$ sodium fluoride, $10 \mathrm{mM}$ paranitrophenylphosphate, $1 \mathrm{mM}$ dithiotreitol, $1 \mathrm{mM}$ phenylmethylsulfonyl fluoride, $1 \mu \mathrm{g} / \mathrm{ml}$ of leupeptin and pepstatin, followed by incubation for $30 \mathrm{~min}$ on ice. Proteins $(40 \mu \mathrm{g})$ were separated on $12 \%$ SDS-PAGE and then transferred onto a nitrocellulose membrane. Blots were probed with a polyclonal anti-RhoB antibody overnight and then with horseradish 
peroxidase-labelled goat anti-rabbit IgG. After incubation in the ECL system, membranes were exposed to Hyperfilm MP.

\section{Immunoprecipitation of farnesylated RhoB}

$\mathrm{NIH}-3 \mathrm{~T} 3$ cells were lysed with Reporter Lysis Buffer (Promega) containing protease inhibitors. After centrifugation of the lysate at $18000 \times g$ for $10 \mathrm{~min}$, the supernatant was delipidated with ice-cold acetone overnight. The protein pellets were then solubilized in Reporter Lysis Buffer and clarified by centrifugation at $10000 \times g$ for $10 \mathrm{~min}$. Protein concentration was determined using the Bradford assay. In all, $500 \mu \mathrm{g}$ of proteins was incubated for $48 \mathrm{~h}$ with the rabbit F-Cys $\mathrm{Ab}^{17}$ in $1 \mathrm{ml}$ of $30 \mathrm{mM}$ Hepes, $\mathrm{pH}$ 7.5 , containing $30 \mathrm{mM} \mathrm{NaCl}, 0.1 \%$ Triton $X-100$. Sheep anti-rabbit IgG antibody coupled to magnetic beads (Dynabeads M280, Dynal) $(20 \mu \mathrm{l})$ was then added. After a $1 \mathrm{~h}$ incubation and four washes with $1 \mathrm{ml} 30 \mathrm{mM}$ Hepes, pH 7.5 containing $30 \mathrm{mM} \mathrm{NaCl}, 0.1 \%$ Triton $X-100$, the immune complexes were dissociated with $30 \mu \mathrm{l} 0.3 \mathrm{M}$ Tris, pH 6.8 containing $8 \mathrm{M}$ urea, $50 \mathrm{mM}$ iodoacetamide, $40 \%$ glycerol, $0.02 \%$ bromophenol blue. The whole extract was then analyzed using Western blotting and a rabbit polyclonal anti-RhoB antibody.

\section{Radiation survival determination}

Limited dilution cloning was used to measure the fraction of cells surviving at $2 \mathrm{~Gy}$, as described earlier. ${ }^{7}$ Cells from exponential cultures either untreated or treated with 1nM R115777 were then plated in 96-well dishes in a volume of $20 \mu \mathrm{l}$ and allowed to grow for $24 \mathrm{~h}$. Dishes were irradiated or sham irradiated and fresh medium was added to a final volume of $200 \mu \mathrm{l}$. Plates were then scored for the presence of colonies after 8-10 days. Linear regression analysis was performed on the natural log of negative wells with the origin as the initial point of the line. The survival fraction at 2 Gy (SF2) was defined as the slope of the line obtained from irradiated cultures divided by the slope of the line obtained from sham-irradiated cultures.

\section{DAPI staining and necrosis detection}

Cells $\left(10^{4}\right)$ were grown on glass coverlips in culture medium for $12 \mathrm{~h}$ and then either treated with $\mathrm{Y} 2763210 \mu \mathrm{M}$ for $30 \mathrm{~min}$ or left untreated before being irradiated with $8 \mathrm{~Gy}$. At various times following irradiation, cells were then washed in PBS and fixed in paraformaldhehyde ( $3 \% \mathrm{w} / \mathrm{v}$ in PBS) for $15 \mathrm{~min}$ at room temperature. Coverslips were then rinsed three times with PBS before incubation with $0.1 \mu \mathrm{g} / \mathrm{ml}$ DAPI (Roche Diagnostic, France) at $37^{\circ} \mathrm{C}$. Cells were viewed using a Zeiss microscope.

For necrosis detection, medium was changed $120 \mathrm{~h}$ after irradiation by DMEM containing $10 \%$ FCS and propidium iodide $50 \mu \mathrm{g} / \mathrm{ml}$. Cellular permeability for propidium iodide was evaluated on a Zeiss microscope.

\section{Cell cycle analysis}

At $24 \mathrm{~h}$ before irradiation, cells were harvested in a logarithmic monolayer growth and reseeded into $25 \mathrm{~cm}^{2}$ culture flasks at $5 \times 10^{5}$ cells/flask. Cells were irradiated at $8 \mathrm{~Gy}$ or sham irradiated and then returned to the incubator. At various times after this irradiation, cells were harvested, pooled, and fixed in $75 \%$ ethanol for $30 \mathrm{~min}$ at $4^{\circ} \mathrm{C}$. These cells were next incubated at $37^{\circ} \mathrm{C}$ with $100 \mu \mathrm{g} / \mathrm{ml}$ RNase $\mathrm{A}$ for $30 \mathrm{~min}$, after which propidium iodide $(50 \mu \mathrm{g} / \mathrm{ml})$ and Tween $20(0.5 \%)$ were added for $30 \mathrm{~min}$. Samples were then analyzed using a Facscalibur (Beckton Dickinson, France).

\section{Immunofluorescence microscopy}

Cells on coverslips were fixed with $4 \%$ paraformaldhedyde in PBS for 15 min prior to incubation with a permeabilization buffer (PBS containing $0.1 \%$. Triton X-100) for $5 \mathrm{~min}$, then with a blocking solution (50\% FCS in PBS) for $30 \mathrm{~min}$ and before the application of the following primary antibodies: anti- $\gamma$-tubulin clone ${ }^{25}$ at a $1 / 1000$ dilution for $2 \mathrm{~h}$ or with the mouse anti-RhoB (Santa-Cruz) $1 / 50$ in PBS $10 \%$ FCS at $4{ }^{\circ} \mathrm{C}$ overnight. Cells were then incubated with the secondary antibodies, anti-rabbit TRITC (Rockland, USA) at a 1/500 dilution for $1 \mathrm{~h}$ or with FITC mouse antibodies (Sigma) at 1/200.To analyze the centrosome overduplication, cells containing an abnormal number of centrosomes were quantified by determining the number of cells with more than two centrosomes in a 100 -cells field.

\section{Immunofluorescent detection of phospho-H3}

Cells were harvested at different times after irradiation, washed with phosphate-buffered saline (PBS), and fixed in suspension $\left(10^{6} \mathrm{cell} / \mathrm{ml}\right)$ by the addition of $2 \mathrm{ml}$ of $70 \%$ ethanol and by incubation at $-20^{\circ} \mathrm{C}$ for as long as $24 \mathrm{~h}$. After fixation, the cells were washed twice with PBS containing $0.5 \%$ bovine serum albumin (BSA) and $2 \%$ FCS, suspended in $0.1 \%$ Triton X-100 in PBS/0.5\% BSA/2\% FCS, and incubated on ice for $5 \mathrm{~min}$. After centrifugation, the cell pellet was suspended in PBS containing $2 \%$ bovine serum albumin (BSA) and 10\% FCS and incubated for 20 min on ice. After saturation, the cell pellet was incubated with monoclonal antibody that specifically recognizes the phosphorylated form of histone $\mathrm{H} 3$ (phospho-H3 (Ser10)), diluted at a ratio of $1 / 25$ and incubated for $2 \mathrm{~h}$ on ice. The cells were then rinsed with PBS $/ 0.5 \%$ BSA $/ 2 \%$ FCS and incubated with fluorescein isothiocyanate-conjugated anti-mouse $\operatorname{lgG}$ antibody diluted at a ratio of $1: 200$ in PBS $/ 0.5 \%$ BSA $/ 2 \%$ FCS. After a 30-min incubation on ice in the dark, the cells were washed again, resuspended in $50 \mu \mathrm{g} / \mathrm{ml}$ of propidium iodide (PI) and in PBS $/ 0.5 \% \mathrm{BSA} /$ $2 \%$ FCS, and incubated on ice for 5 min before the fluorescence was measured using a flow cytometer (Becton Dickinson, France).

\section{Statistical analysis}

Student's $t$-test was performed to compare the means of values from different experiments.

\section{Acknowledgements}

This work was supported by the Ministere de la Recherche et de l'Enseignement Supérieur (GF), by the Ligue Nationale Contre le Cancer (équipe labellisée), by the Ligue Contre le Cancer, Comité Tarn et Garonne (JM) and Comité de Loire (FT), by Electricité de France, by the Agence Nationale de Valorisation de la Recherche (FT) and by the Groupe de Recherche de l'Institut Claudius Regaud (GF, ECJ, CT). We particularly thank Dr. D End (Johnson \& Johnson Pharmaceutical Research \& Development USA) for providing the specific farnesyltransferase inhibitor, R115777.

\section{References}

1. Dikomey E, Borgmann K, Brammer I and Kasten-Pisula U (2003) Molecular mechanisms of individual radiosensitivity studied in normal diploid human fibroblasts. Toxicology 193: 125-135 
2. Jonathan EC, Bernhard EJ and McKenna WG (1999) How does radiation kill cells? Curr. Opin. Chem. Biol. 3: 77-83

3. Tounekti O, Pron G, Belehradek Jr J and Mir LM (1993) Bleomycin, an apoptosis-mimetic drug that induces two types of cell death depending on the number of molecules internalized. Cancer Res. 53: 5462-5469

4. Lock RB and Stribinskiene $L$ (1996) Dual modes of death induced by etoposide in human epithelial tumor cells allow Bcl-2 to inhibit apoptosis without affecting clonogenic survival. Cancer Res. 56: 4006-4012

5. Torres K and Horwitz SB (1998) Mechanisms of Taxol-induced cell death are concentration dependent. Cancer Res. 58: 3620-3626

6. Cohen-Jonathan E, Toulas C, Ader I, Monteil S, Allal C, Bonnet J, Hamilton AD, Sebti SM, Daly-Schveitzer N and Favre G (1999) The farnesyltransferase inhibitor FTI-277 suppresses the 24-kDa FGF2-induced radioresistance in HeLa cells expressing wild-type RAS. Radiat Res. 152: 404-411

7. Delmas C, Heliez C, Cohen-Jonathan E, End D, Bonnet J, Favre G and Toulas C (2002) Farnesyltransferase inhibitor, R115777, reverses the resistance of human glioma cell lines to ionizing radiation. Int. J. Cancer 100: 43-48

8. Roninson IB, Broude EV and Chang BD (2001) If not apoptosis, then what? Treatment-induced senescence and mitotic catastrophe in tumor cells. Drug Resist. Update 4: 303-313

9. Sato N, Mizumoto K, Nakamura M, Ueno H, Minamishima YA, Farber JL and Tanaka M (2000) A possible role for centrosome overduplication in radiationinduced cell death. Oncogene 19: 5281-5290

10. Sato N, Mizumoto K, Nakamura M and Tanaka M (2000) Radiation-induced centrosome overduplication and multiple mitotic spindles in human tumor cells. Exp. Cell. Res. 255: 321-326

11. Bernhard EJ, Kao G, Cox AD, Sebti SM, Hamilton AD, Muschel RJ and McKenna WG (1996) The farnesyltransferase inhibitor FTI-277 radiosensitizes H-ras-transformed rat embryo fibroblasts. Cancer Res. 56: 1727-1730

12. Bernhard EJ, McKenna WG, Hamilton AD, Sebti SM, Qian Y, Wu JM and Muschel RJ (1998) Inhibiting Ras prenylation increases the radiosensitivity of human tumor cell lines with activating mutations of ras oncogenes. Cancer Res. 58: $1754-1761$

13. Lebowitz PF and Prendergast GC (1998) Non-Ras targets of farnesyltransferase inhibitors: focus on Rho. Oncogene 17: 1439-1445

14. Van Aelst L and D'Souza-Schorey C (1997) Rho GTPases and signaling networks. Genes Dev. 11: 2295-2322

15. Fritz G, Kaina B and Aktories K (1995) The ras-related small GTP-binding protein $\mathrm{RhoB}$ is immediate-early inducible by DNA damaging treatments. J. Biol. Chem. 270: 25172-25177

16. Adamson P, Marshall CJ, Hall A and Tilbrook PA (1992) Post-translational modifications of p21rho proteins. J. Biol. Chem. 267: 20033-20038

17. Baron R, Fourcade E, Lajoie-Mazenc I, Allal C, Couderc B, Barbaras R, Favre G, Faye JC and Pradines A (2000) RhoB prenylation is driven by the three carboxyl-terminal amino acids of the protein: evidenced in vivo by an antifarnesyl cysteine antibody. Proc. Natl. Acad. Sci. USA 97: 11626-11631

18. Liu A and Prendergast GC (2000) Geranylgeranylated RhoB is sufficient to mediate tissue-specific suppression of Akt kinase activity by farnesyltransferase inhibitors. FEBS Lett. 481: 205-208

19. Liu A, Cerniglia GJ, Bernhard EJ and Prendergast GC (2001) RhoB is required to mediate apoptosis in neoplastically transformed cells after DNA damage. Proc. Natl. Acad. Sci. USA 98: 6192-6197

20. Chen Z, Sun J, Pradines A, Favre G, Adnane J and Sebti SM (2000) Both farnesylated and geranylgeranylated RhoB inhibit malignant transformation and suppress human tumor growth in nude mice. J. Biol. Chem. 275: 17974-17978

21. Ader I, Toulas C, Dalenc F, Delmas C, Bonnet J, Cohen-Jonathan E and Favre $\mathrm{G}$ (2002) RhoB controls the $24 \mathrm{kDa}$ FGF-2-induced radioresistance in HeLa cells by preventing post-mitotic cell death. Oncogene 21: 5998-6006

22. Ader I, Delmas C, Bonnet J, Rochaix P, Favre G, Toulas C and CohenJonathan-Moyal E (2003) Inhibition of Rho pathways induces radiosensitization and oxygenation in human glioblastoma xenografts. Oncogene 22: 8861-8869

23. End DW, Smets G, Todd AV, Applegate TL, Fuery CJ, Angibaud P, Venet M Sanz G, Poignet H, Skrzat S, Devine A, Wouters W and Bowden C (2001)
Characterization of the antitumor effects of the selective farnesyl protein transferase inhibitor R115777 in vivo and in vitro. Cancer Res. 61: 131-137

24. Allal C, Pradines A, Hamilton AD, Sebti SM and Favre G (2002) Farnesylated RhoB prevents cell cycle arrest and actin cytoskeleton disruption caused by the geranylgeranyltransferase I inhibitor GGTI-298. Cell Cycle 1: 430-437

25. Lajoie-Mazenc I, Tollon Y, Detraves C, Julian M, Moisand A, Gueth-Hallonet C, Debec A, Salles-Passador I, Puget A, Mazarguil H, Raynaud-Messina B and Wright M (1994) Recruitment of antigenic gamma-tubulin during mitosis in animal cells: presence of gamma-tubulin in the mitotic spindle. J. Cell. Sci. 107 (Part 10): 2825-2837

26. Hwang A and Muschel RJ (1998) Radiation and the G2 phase of the cell cycle. Radiat. Res. 150: S52-S59

27. Maity A, Kao GD, Muschel RJ and McKenna WG (1997) Potential molecular targets for manipulating the radiation response. Int. J. Radiat. Oncol. Biol. Phys. 37: 639-653

28. Wherlock M, Gampel A, Futter C and Mellor H (2004) Farnesyltransferase inhibitors disrupt EGF receptor traffic through modulation of the RhoB GTPase. J. Cell. Sci. 117: 3221-3231

29. Matsui T, Amano M, Yamamoto T, Chihara K, Nakafuku M, Ito M, Nakano T, Okawa K, Iwamatsu A and Kaibuchi K (1996) Rho-associated kinase, a novel serine/threonine kinase, as a putative target for small GTP binding protein Rho. EMBO J. 15: 2208-2216

30. Inada H, Togashi H, Nakamura Y, Kaibuchi K, Nagata K and Inagaki M (1999) Balance between activities of Rho kinase and type 1 protein phosphatase modulates turnover of phosphorylation and dynamics of desmin/vimentin filaments. J. Biol. Chem. 274: 34932-34939

31. Chevrier V, Piel M, Collomb N, Saoudi Y, Frank R, Paintrand M, Narumiya S, Bornens M and Job D (2002) The Rho-associated protein kinase p160ROCK is required for centrosome positioning. J. Cell Biol. 157: 807-817

32. Ishizaki T, Uehata M, Tamechika I, Keel J, Nonomura K, Maekawa M and Narumiya S (2000) Pharmacological properties of Y-27632, a specific inhibitor of rho-associated kinases. Mol. Pharmacol. 57: 976-983

33. Strunz AM, Peschke P, Waldeck W, Ehemann V, Kissel M and Debus J (2002) Preferential radiosensitization in p53-mutated human tumour cell lines by pentoxifylline-mediated disruption of the G2/M checkpoint control. Int. J. Radiat. Biol. 78: 721-732

34. Geldof AA, Plaizier MA, Duivenvoorden I, Ringelberg M, Versteegh RT, Newling DW and Teule GJ (2003) Cell cycle perturbations and radiosensitization effects in a human prostate cancer cell line. J. Cancer Res. Clin. Oncol. 129: 175-182

35. Lange BM (2002) Integration of the centrosome in cell cycle control, stress response and signal transduction pathways. Curr. Opin. Cell Biol. 14: 35-43

36. Pihan GA, Purohit A, Wallace J, Malhotra R, Liotta L and Doxsey SJ (2001) Centrosome defects can account for cellular and genetic changes that characterize prostate cancer progression. Cancer Res. 61: 2212-2219

37. Pihan GA, Wallace J, Zhou Y and Doxsey SJ (2003) Centrosome abnormalities and chromosome instability occur together in pre-invasive carcinomas. Cancer Res. 63: 1398-1404

38. Pihan GA, Purohit A, Wallace J, Knecht H, Woda B, Quesenberry P and Doxsey SJ (1998) Centrosome defects and genetic instability in malignant tumors. Cancer Res. 58: 3974-3985

39. Cahill DP, Kinzler KW, Vogelstein B and Lengauer C (1999) Genetic instability and darwinian selection in tumours. Trends Cell Biol. 9: M57-M60

40. Dodson H, Bourke E, Jeffers LJ, Vagnarelli P, Sonoda E, Takeda S, Earnshaw WC, Merdes A and Morrison C (2004) Centrosome amplification induced by DNA damage occurs during a prolonged G2 phase and involves ATM. EMBO J. 23: 3864-3873

41. Brinkley BR (2001) Managing the centrosome numbers game: from chaos to stability in cancer cell division. Trends Cell Biol. 11: 18-21

42. Du J and Hannon GJ (2004) Suppression of p160ROCK bypasses cell cycle arrest after Aurora-A/STK15 depletion. Proc. Natl. Acad. Sci. USA 101: 8975-8980

43. Riento K and Ridley AJ (2003) Rocks: multifunctional kinases in cell behaviour. Nat. Rev. Mol. Cell. Biol. 4: 446-456 